\title{
Oncogenic HMGA2: short or small?
}

\author{
Andrew R.J. Young and Masashi Narita ${ }^{1}$ \\ Cancer Research UK, Cambridge Research Institute, Li Ka Shing Centre, Cambridge CB2 ORE, United Kingdom
}

The High Mobility Group A (HMGA) family of proteins are architectural transcription factors that bind to DNA and introduce structural alterations in chromatin. The HMGA family consists of two members, HMGA1 and HMGA2, which are encoded by separate genes. As one of the major nonhistone chromosomal proteins, HMGA proteins are multifunctional and are involved in many fundamental cellular processes, including gene regulation, cell cycle, differentiation, and viral integration (Reeves 2001). Not surprisingly, therefore, HMGA mutations contribute to many common diseases, including benign and malignant tumors (Sgarra et al. 2004), obesity (Anand and Chada 2000), diabetes (Foti et al. 2005), and atherosclerosis (Schlueter et al. 2005). HMGA proteins are relatively abundant in the early embryo, where cells are proliferating rapidly, whereas they are undetectable in terminally differentiated cells (Sgarra et al. 2004). hmga2-deficient mouse embryonic fibroblasts (MEFs) grow more slowly than wild-type MEFs (Zhou et al. 1995), suggesting that HMGA2 confers a growth advantage. Consistent with this observation, HMGA is indeed oncogenic and is up-regulated in many tumors (see below). However, it was recently shown that HMGA proteins are also involved in cellular senescence, a state of "permanent" cell cycle arrest, adding further diversity to the many facets of the HMGA proteins (Narita et al. 2006).

HMGA proteins are primarily, but not exclusively, upregulated in tumors of mesenchymal origin. Up-regulation of the HMGA gene products often results from genetic alterations such as gene amplification and translocation. Rearrangement of the HMGA2 gene by reciprocal translocations in particular, is frequently observed in benign tumors such as lipomas, lung hamartomas, uterine leiomyomas, endothelial polyps, fibroadenomas, and adenolipomas of the breast (Ashar et al. 1995; Kazmierczak et al. 1995, 1996; Schoenmakers et al. 1995). HMGA is also involved in malignant tumors such as liposarcomas and osteosarcomas, acute lymphoblastic leukemia, as well as many lung carcinomas (Berner et al. 1997; Xu et al. 2004; Sarhadi et al. 2006). The HMGA2 gene, which is located in the q13-15 segment of chromosome 12, consists of five exons. Each of the first three exons encodes for an AT-hook domain, so called because they bind to

${ }^{1}$ Corresponding author.

E-MAIL masashi.narita@cancer.org.uk; FAX 44-1223-404208.

Article is online at http://www.genesdev.org/cgi/doi/10.1101/gad.1554707. the minor groove of AT-rich stretches of DNA. Exons 4 and 5 encode the linker and acidic tail regions, respectively. In most HMGA2 translocations, the breakpoint occurs within the $\sim 140-\mathrm{kb}$ third intron, giving rise to chimeric transcripts that are a fusion of HMGA2's three AT-hooks with various other genes (Goodwin 1998). It was therefore presumed that the fusion proteins themselves were the cause of the tumorigenicity, as exemplified by the classical oncogenic translocations PMLRARa and BCR-ABL. Surprisingly, however, a truncated form of HMGA2, containing only the three AT-hook domains, was sufficient for transformation in vitro. This finding raises the possibility that the loss of the acidic tail, rather than the generation of chimeric proteins, is the critical step in causing HMGA oncogenicity (Fedele et al. 1998). To date, multiple hmga2 transgenic mouse models have been generated, which constitutively express either the full-length or the truncated form of the protein (Arlotta et al. 2000; Fedele et al. 2002). Although these mice all develop benign tumors, their tumor spectrum is slightly different; the truncated form of HMGA2 gives rise to gigantism associated with lipomatosis, while full-length HMGA2 leads to pituitary tumors with milder lipomatosis. Recently, new transgenic mouse models were generated, in which either a full-length or a truncated from of HMGA2 was expressed under a promoter specific for differentiated mesenchymal tissues (Zaidi et al. 2006). Both transgenic models developed various benign mesenchymal tumors, yet the severity of the tumor phenotype was not affected by the presence or absence of the $\mathrm{C}$-terminal acidic tail. These findings, in contrast to the original hmga2 transgenic models that ubiquitously and constitutively express HMGA2, suggest that the misexpression of HMGA2 itself is sufficient for tumorigenesis, at least in the mesenchymal lineage. Thus, how translocations in the HMGA2 locus lead to tumor development is a matter of debate.

Now, Lee and Dutta (2007) in this issue of Genes \& Development, together with others (Hebert et al. 2007; Lee and Dutta 2007; Mayr et al. 2007; Wang et al. 2007), provide new insight into this long-standing debate, indicating that the chromosomal translocations within HMGA2 may contribute to tumorigenesis by removing $H M G A 2$ 's 3' untranslated region (UTR). These reports identify HMGA2 as a target of the let-7 family of microRNAs (miRNAs). miRNAs encode a class of small, regulatory noncoding RNAs, which have come to prominence as a key mechanism of post-transcriptional regu- 
lation within the last decade (Ambros 2004; Bartel 2004; Zamore and Haley 2005). Primary transcripts of miRNA genes (pri-miRNAs) undergo sequential processing to yield mature miRNAs, $18-25$ nucleotides in length. The biogenesis of miRNAs involves two RNase III enzymes, Drosha and Dicer. pri-miRNAs are processed by Drosha into precursor miRNAs (pre-miRNAs), which are subsequently processed by Dicer into the mature miRNAs. The mature miRNAs typically bind, with imperfect base pairing, to the 3'UTRs of specific mRNA targets and repress their expression at the post-transcriptional level (Fig. 1A).

Lee and Dutta (2007) identify that the HMGA2 transcript can be regulated by miRNA through a screen for candidates based on Dicer knockdown in HeLa cells. They subsequently confirm that the HMGA2 mRNA is destabilized only in the cytoplasmic fraction, consistent with the cytosol being the primary site of miRNA function. Computational searches identified multiple putative let-7-binding sites in the 3'UTR of the HMGA2 mRNA (Hebert et al. 2007; Lee and Dutta 2007; Mayr et al. 2007; Wang et al. 2007). Let-7 was one of the first miRNA genes to be discovered in Caenorhabditis elegans, a heterochronic gene regulating the developmental timing of the larvae. The let-7 family's expression is also developmentally regulated in mice (Schulman et al. 2005) and humans (Pasquinelli et al. 2000). The expression of let-7 during development is inversely correlated with that of HMGA2. This observation lead Lee and Dutta (2007) to focus on let-7, and let-7b and let-7e more specifically, and carry out detailed structural and functional analyses of the 3'UTR of the HMGA2 transcript, showing in luciferase reporter assays that six of the eight putative let-7-binding sites are responsible for HMGA2 repression. Mayr et al. (2007) perform a similar analysis, yielding consistent results. Furthermore, disruption of the let-7 repression of HMGA2 enhances cell proliferation in H1299 cells (Lee and Dutta 2007) and causes transformation in NIH-3T3 cells (Mayr et al. 2007).
These results suggest an intriguing possibility: that the "translocation-associated loss of miRNA-mediated repression" may contribute to tumorigenesis (Fig. 1B).

Genomic rearrangement may not be the only thing that affects the miRNA-mediated regulation of HMGA2. Herbert et al. (2007) show in primary human oral squamous carcinoma cells (SCCs) that levels of miR-98 (a miRNA highly related to let-7) increase in hypoxic conditions, characteristic of the microenvironment found in many tumor tissues. The authors also show the up-regulation of let-7 in the same hypoxic context, although to a lesser extent. Interestingly, the hypoxia-induced upregulation of $m i R-98$ correlated with the down-regulation of HMGA2, which causes SCCs chemoresistance. Indeed, Herbert et al. (2007) verify that miR-98 can target $H M G A 2$ in these cells. Although the data are correlative, the study suggests that a hypoxic microenvironment could potentially modulate the characteristics of a tumor through the alteration of its miRNA profile.

Approximately $80 \%$ of the conserved vertebrate miRNAs that are expressed during embryonic development are tissue specific (Wienholds and Plasterk 2005). This tissue specificity is not restricted to only a few major organs, even individual cell types within tissues have specific expression of one or a few miRNAs (Wienholds and Plasterk 2005). The distinct expression profile of miRNAs may also be important in cellular transformation and tumorigenesis. Aberrant expression of some miRNAs is associated with certain types of tumors such as leukemias, lung cancer, and breast cancers /Calin et al. 2004; Cimmino et al. 2005; Iorio et al. 2005; Johnson et al. 2005; Volinia et al. 2006; Yanaihara et al. 2006). Wang et al. (2007) analyze the global miRNA expression pattern of 55 samples of human uterine leiomyomas (ULMs), a tumor in which a HMGA2 translocation is commonly found, and show a homogenous and specific miRNA signature in these tumors. In this study, let-7 is one of the top five deregulated miRNAs in ULMs and, indeed, let-7 is up-regulated in tumors compared with
Figure 1. Translocation-associated loss of miRNAmediated repression. (A) miRNAs are sequentially processed after transcription in both the nucleus and cytoplasm. miRNAs regulate mRNA expression by inhibiting translation and/or causing the degradation of the mRNA. (B) As suggested by a series of new studies, upon translocation within a gene locus, in this case HMGA2, the sites previously recognized by the corresponding miRNA, let-7, can be removed with the result that the mRNA is aberrantly expressed. Conceivably, any translocation within a gene locus may result in the loss of the miRNA-mediated regulation of a gene's expression. This might also be true even for the cases where chimeric gene products have aberrant functions that would be further modified quantitatively by the exchange of the post-transcriptional regulation. Here, HMGA2 is in black and its fusion partner is in red.
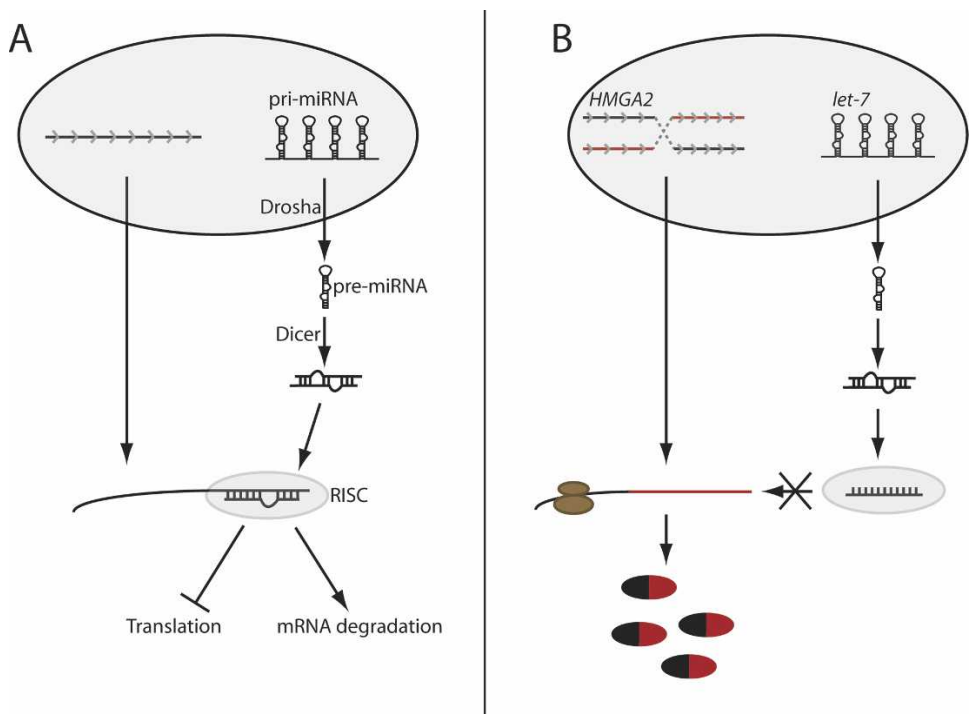
the matched myometrium samples. More careful analysis revealed a correlation between tumor size and let-7/ HMGA2 expression levels; the small tumors tending to exhibit higher let-7 and lower HMGA2 expression, while the large ULMs tend to show the opposite pattern. Although no functional analysis is provided, one tempting interpretation of this data is that, during tumor development, up-regulation of let-7 is triggered, which inhibits the tumor's growth by repressing the expression of HMGA2 and probably other targets. This, then, might be an example where let-7 exhibits an active tumor suppressor function in vivo.

Are miRNAs the only method of post-transcriptional regulation of HMGA2 mRNA? Post-transcriptional repression of genes involves several events, including translational repression and mRNA decay (for review, see Eulalio et al. 2007). It was recently shown that translational repression and mRNA decay are not only functionally, but also physically associated, and miRNAs can be a link between them (Eulalio et al. 2007). The AU-rich element (ARE)-mediated mRNA decay (AMD) pathway, for example, is one of the most studied mechanisms of post-transcriptional regulation. The ARE motif is a cisacting RNA element and the presence of an ARE motif in mRNAs is associated with the rapid turnover of unstable mRNAs in mammalian cells. Recently, a specific miRNA, miR-16, was shown to be involved in the degradation of at least some ARE-containing mRNAs (Jing et al. 2005), although it is not clear whether miR-16 is the sole link between the miRNA and AMD pathways. Similar to miRNA, ARE target sites are often located in the 3'UTR of mRNAs. Interestingly, the post-transcriptional regulation of HMGA2 through its $3^{\prime} \mathrm{UTR}$ was originally implied $10 \mathrm{yr}$ ago (Geurts et al. 1997). It was shown that the HMGA2 transcript contains 10 ARE motifs (AUUUA) in its 3'UTR (Geurts et al. 1997; Borrmann et al. 2001). Borrmann et al. (2001) performed reporter assays using several $3^{\prime}$ deletion mutants of the HMGA2 mRNA, and showed that HMGA2 expression is negatively regulated by its $3^{\prime}$ UTR. Since they used a series of large truncations, it is not possible to say whether the effects of the deletion mutants reflect the loss of the let-7 targeting sites in the $3^{\prime} \mathrm{UTR}$. Thus, a dual regulation of HMGA2 expression by AMD and let-7 is still a possibility. It remains to be shown whether HMGA2 expression is negatively regulated by these two mechanisms independently or whether they cooperatively contribute to the repression of HMGA2 and, as a consequence, in tumor suppressor function.

Whichever is the case, altogether these new studies convincingly show that HMGA2 is a let-7 target (Hebert et al. 2007; Lee and Dutta 2007; Mayr et al. 2007; Wang et al. 2007) and imply that the tumor-suppressive activity of let-7 relies on HMGA2 repression (Lee and Dutta 2007; Mayr et al. 2007), reinforcing the important roles of miRNA in cancer biology (Caldas and Brenton 2005). Furthermore, these studies provide a new view on why HMGA2 translocation leads to so many tumors. Thus, these studies, in conjunction with the unique history of the studies of HMGA2 oncogenicity, raise an important question: Is the "translocation-associated loss of miRNA-mediated repression" a general mechanism in tumor development? Conceivably, any cancer-related translocation may result in the loss, or more precisely speaking, exchange, of the miRNA-mediated regulation of a gene's expression (Fig. 1B). This might also be true even for the cases where chimeric gene products have aberrant functions, which would be further modified quantitatively by the exchange of the post-transcriptional regulation. In addition, how commonly does the let-7 defect contribute to $H M G A 2$ up-regulation and tumorigenesis without any genomic alteration of the HMGA2 locus. Finally, how does HMGA2 confer a growth advantage to cells? Although there is not much insight into the molecular basis for the oncogenic activity of HMGA proteins, a potential role of its C-terminal acidic tail in tumorigenesis has been suggested, and an enhanced transformation activity of such a truncation of HMGA2 has been shown in vitro and in xenograft systems (Fedele et al. 1998). In addition, truncated HMGA1 was also shown to dramatically increase the growth rate of 3T3-L1 cells, a model of adipogenisis in vitro (Pierantoni et al. 2003). HMGA proteins participate in the regulation of many genes through their physical association with DNA, as well as with a large number of proteins. The acidic tail is thought to have an influence on HMGA's protein-DNA or protein-protein binding and, indeed, it has been shown that the acidic tail can modify the "architectural transcription" activity of HMGA proteins for certain specific target genes (Yie et al. 1997; Borrmann et al. 2003). In addition, the rearrangement in the HMGA2 locus in malignant tumors is very complicated, and this can involve not only HMGA2 breakpoints, but also the status of its neighboring genes, $M D M 2$ and $C D K 4$, both of which are often coamplified with HMGA2 in tumors (Berner et al. 1997). Interestingly, ectopic expression of MDM2 and CDK4 can mask the ability of HMGA2 to enhance the senescence phenotype of human diploid fibroblasts (HDFs) (Narita et al. 2006). Also, full-length HMGA2 can contribute to the malignant transformation of the HDFs cooperatively with oncogenic ras, only when the senescence pathway is completely blocked (Narita et al. 2006). Therefore, full-length HMGA2 function is largely context dependent, which might in part be attributable to its acidic tail. Thus, the discovery of the post-transcriptional regulation of HMGA2 through the 3'UTR does not necessarily detract from the importance of the potential role of the acidic tail in the oncogenic properties of HMGA proteins in some cellular contexts. Perhaps more physiological settings will be required to tackle the precise role of the acidic tail in malignant transformation.

The series of new studies discussed here (Hebert et al. 2007; Lee and Dutta 2007; Mayr et al. 2007; Wang et al. 2007) provide convincing evidence of the link between let-7 and HMGA2 using cultured cells. However, the clinical and in vivo significance of the let-7/HMGA2 connection remains to be addressed. Both the up-regulation of HMGA2 and the down-regulation of let-7 have been reported in independent studies of lung cancer, for 
example. Indeed, both are associated with poor prognosis (Takamizawa et al. 2004; Sarhadi et al. 2006). This inverse correlation between HMGA2 and let-7 expression is very interesting, but the analysis of the direct link between these two transcripts in the same tumor tissues still remains to be determined. Does the deficiency of the let-7 cluster contribute to cancer development and is HMGA2 required for this phenotype in vivo? Is HMGA2 the sole target for the let-7 phenotype in cancer? Given the flexibility of the target specificity of each miRNA and the diversity of the highly related miRNAs, it would be necessary to view the relation between mRNA targets and miRNAs as a network. In this sense, for example, what is the role of ras, another important oncogene in lung cancer, which has also been shown to be a target of let-7 (Johnson et al. 2005)? Do HMGA2 and ras cooperate in certain lung cancers and, also, is let-7 a key element for the cooperative action between them? Paradoxically, both the HMGA2 and ras oncogenes contribute to the cellular senescence phenotype. What is a role of let-7 in senescence, if any, both in vitro and in vivo? Currently, there are few mouse models available to study the roles of miRNAs in cancer (He et al. 2005); genetically modified mouse models for specific miRNAs, the let-7 cluster in this case, in conjunction with the hmga2 transgenic and knockout mice will be necessary to address these questions. An important note is that the transgenes of the existing hmga2 transgenic mice apparently only contain the open reading frames and, consequently, are free of let-7 regulation. Cancer is a complicated disease and the miRNA regulation of cancer-related genes certainly adds another layer of complexity, but understanding its in vivo significance will extend our outlook and increase our chances of finding targets for cancer therapy.

\section{Acknowledgments}

We thank Drs. C. Caldas and L. He for comments on the manuscript.

\section{References}

Ambros, V. 2004. The functions of animal microRNAs. Nature 431: 350-355.

Anand, A. and Chada, K. 2000. In vivo modulation of Hmgic reduces obesity. Nat. Genet. 24: 377-380.

Arlotta, P., Tai, A.K., Manfioletti, G., Clifford, C., Jay, G., and Ono, S.J. 2000. Transgenic mice expressing a truncated form of the high mobility group I-C protein develop adiposity and an abnormally high prevalence of lipomas. J. Biol. Chem. 275: 14394-14400.

Ashar, H.R., Fejzo, M.S., Tkachenko, A., Zhou, X., Fletcher, J.A., Weremowicz, S., Morton, C.C., and Chada, K. 1995. Disruption of the architectural factor HMGI-C: DNA-binding AT hook motifs fused in lipomas to distinct transcriptional regulatory domains. Cell 82: 57-65.

Bartel, D.P. 2004. MicroRNAs: Genomics, biogenesis, mechanism, and function. Cell 116: 281-297.

Berner, J.M., Meza-Zepeda, L.A., Kools, P.F., Forus, A., Schoenmakers, E.F., Van de Ven, W.J., Fodstad, O., and Myklebost, O. 1997. HMGIC, the gene for an architectural transcription factor, is amplified and rearranged in a subset of human sarcomas. Oncogene 14: 2935-2941.

Borrmann, L., Wilkening, S., and Bullerdiek, J. 2001. The expression of HMGA genes is regulated by their 3'UTR. Oncogene 20: 4537-4541.

Borrmann, L., Schwanbeck, R., Heyduk, T., Seebeck, B., Rogalla, P., Bullerdiek, J., and Wisniewski, J.R. 2003. High mobility group A2 protein and its derivatives bind a specific region of the promoter of DNA repair gene ERCC1 and modulate its activity. Nucleic Acids Res. 31: 6841-6851.

Caldas, C. and Brenton, J.D. 2005. Sizing up miRNAs as cancer genes. Nat. Med. 11: 712-714.

Calin, G.A., Sevignani, C., Dumitru, C.D., Hyslop, T., Noch, E. Yendamuri, S., Shimizu, M., Rattan, S., Bullrich, F., Negrini, M., et al. 2004. Human microRNA genes are frequently located at fragile sites and genomic regions involved in cancers. Proc. Natl. Acad. Sci. 101: 2999-3004.

Cimmino, A., Calin, G.A., Fabbri, M., Iorio, M.V., Ferracin, M. Shimizu, M., Wojcik, S.E., Aqeilan, R.I., Zupo, S., Dono, M., et al. 2005. miR-15 and miR-16 induce apoptosis by targeting BCL2. Proc. Nat1. Acad. Sci. 102: 13944-13949.

Eulalio, A., Behm-Ansmant, I., and Izaurralde, E. 2007. P bodies: At the crossroads of post-transcriptional pathways. Nat. Rev. Mol. Cell Biol. 8: 9-22.

Fedele, M., Berlingieri, M.T., Scala, S., Chiariotti, L., Viglietto, G., Rippel, V., Bullerdiek, J., Santoro, M., and Fusco, A. 1998. Truncated and chimeric HMGI-C genes induce neoplastic transformation of NIH3T3 murine fibroblasts. Oncogene 17: 413-418.

Fedele, M., Battista, S., Kenyon, L., Baldassarre, G., Fidanza, V., Klein-Szanto, A.J., Parlow, A.F., Visone, R., Pierantoni, G.M., Outwater, E., et al. 2002. Overexpression of the HMGA2 gene in transgenic mice leads to the onset of pituitary adenomas. Oncogene 21: 3190-3198.

Foti, D., Chiefari, E., Fedele, M., Iuliano, R., Brunetti, L., Paonessa, F., Manfioletti, G., Barbetti, F., Brunetti, A., Croce, C.M., et al. 2005. Lack of the architectural factor HMGA1 causes insulin resistance and diabetes in humans and mice. Nat. Med. 11: 765-773.

Geurts, J.M., Schoenmakers, E.F., and Van de Ven, W.J. 1997. Molecular characterization of a complex chromosomal rearrangement in a pleomorphic salivary gland adenoma involving the 3'-UTR of HMGIC. Cancer Genet. Cytogenet. 95: 198-205.

Goodwin, G. 1998. The high mobility group protein, HMGI-C. Int. J. Biochem. Cell Biol. 30: 761-766.

He, L., Thomson, J.M., Hemann, M.T., Hernando-Monge, E., $\mathrm{Mu}, \mathrm{D} .$, Goodson, S., Powers, S., Cordon-Cardo, C., Lowe, S.W., Hannon, G.J., et al. 2005. A microRNA polycistron as a potential human oncogene. Nature 435: 828-833.

Hebert, C., Norris, K., Scheper, M.A., Nikitakis, N., and Sauk, J.J. 2007. High mobility group A2 is a target for miRNA-98 in head and neck squamous cell carcinoma. Mol. Cancer 6: 5.

Iorio, M.V., Ferracin, M., Liu, C.G., Veronese, A., Spizzo, R., Sabbioni, S., Magri, E., Pedriali, M., Fabbri, M., Campiglio, M., et al. 2005. MicroRNA gene expression deregulation in human breast cancer. Cancer Res. 65: 7065-7070.

Jing, Q., Huang, S., Guth, S., Zarubin, T., Motoyama, A., Chen, J., Di Padova, F., Lin, S.C., Gram, H., and Han, J. 2005. Involvement of microRNA in AU-rich element-mediated mRNA instability. Cell 120: 623-634.

Johnson, S.M., Grosshans, H., Shingara, J., Byrom, M., Jarvis, R., Cheng, A., Labourier, E., Reinert, K.L., Brown, D., and Slack, F.J. 2005. RAS is regulated by the let-7 microRNA family Cell 120: 635-647.

Kazmierczak, B., Wanschura, S., Rosigkeit, J., Meyer-Bolte, K., 
Uschinsky, K., Haupt, R., Schoenmakers, E.F., Bartnitzke, S., Van de Ven, W.J., and Bullerdiek, J. 1995. Molecular characterization of $12 \mathrm{q} 14-15$ rearrangements in three pulmonary chondroid hamartomas. Cancer Res. 55: 2497-2499.

Kazmierczak, B., Rosigkeit, J., Wanschura, S., Meyer-Bolte, K., Van de Ven, W.J., Kayser, K., Krieghoff, B., Kastendiek, H., Bartnitzke, S., and Bullerdiek, J. 1996. HMGI-C rearrangements as the molecular basis for the majority of pulmonary chondroid hamartomas: A survey of 30 tumors. Oncogene 12: $515-521$.

Lee, Y.S. and Dutta, A. 2007. The tumor suppressor microRNA let-7 represses the HMGA2 oncogene. Genes \& Dev. (this issue).

Mayr, C., Hemann, M.T., and Bartel, D.P. 2007. Disrupting the pairing between let-7 and Hmga2 enhances oncogenic transformation. Science 315: 1576-1579.

Narita, M., Narita, M., Krizhanovsky, V., Nunez, S., Chicas, A., Hearn, S.A., Myers, M.P., and Lowe, S.W. 2006. A novel role for high-mobility group a proteins in cellular senescence and heterochromatin formation. Cell 126: 503-514.

Pasquinelli, A.E., Reinhart, B.J., Slack, F., Martindale, M.Q., Kuroda, M.I., Maller, B., Hayward, D.C., Ball, E.E., Degnan, B., Muller, P., et al. 2000. Conservation of the sequence and temporal expression of let-7 heterochronic regulatory RNA. Nature 408: 86-89.

Pierantoni, G.M., Battista, S., Pentimalli, F., Fedele, M., Visone, R., Federico, A., Santoro, M., Viglietto, G., and Fusco, A. 2003. A truncated HMGA1 gene induces proliferation of the 3T3-L1 pre-adipocytic cells: A model of human lipomas. Carcinogenesis 24: 1861-1869.

Reeves, R. 2001. Molecular biology of HMGA proteins: Hubs of nuclear function. Gene 277: 63-81.

Sarhadi, V.K., Wikman, H., Salmenkivi, K., Kuosma, E., Sioris, T., Salo, J., Karjalainen, A., Knuutila, S., and Anttila, S. 2006. Increased expression of high mobility group A proteins in lung cancer. J. Pathol. 209: 206-212.

Schlueter, C., Hauke, S., Loeschke, S., Wenk, H.H., and Bullerdiek, J. 2005. HMGA1 proteins in human atherosclerotic plaques. Pathol. Res. Pract. 201: 101-107.

Schoenmakers, E.F., Wanschura, S., Mols, R., Bullerdiek, J., Van den Berghe, H., and Van de Ven, W.J. 1995. Recurrent rearrangements in the high mobility group protein gene, HMGI-C, in benign mesenchymal tumours. Nat. Genet. 10: 436-444.

Schulman, B.R., Esquela-Kerscher, A., and Slack, F.J. 2005. Reciprocal expression of lin-41 and the microRNAs let-7 and mir-125 during mouse embryogenesis. Dev. Dyn. 234: 10461054.

Sgarra, R., Rustighi, A., Tessari, M.A., Di Bernardo, J., Altamura, S., Fusco, A., Manfioletti, G., and Giancotti, V. 2004. Nuclear phosphoproteins HMGA and their relationship with chromatin structure and cancer. FEBS Lett. 574: 1-8.

Takamizawa, J., Konishi, H., Yanagisawa, K., Tomida, S., Osada, H., Endoh, H., Harano, T., Yatabe, Y., Nagino, M., Nimura, Y., et al. 2004. Reduced expression of the let-7 microRNAs in human lung cancers in association with shortened postoperative survival. Cancer Res. 64: 3753-3756.

Volinia, S., Calin, G.A., Liu, C.G., Ambs, S., Cimmino, A., Petrocca, F., Visone, R., Iorio, M., Roldo, C., Ferracin, M., et al. 2006. A microRNA expression signature of human solid tumors defines cancer gene targets. Proc. Natl. Acad. Sci. 103: 2257-2261.

Wang, T., Zhang, X., Obijuru, L., Laser, J., Aris, V., Lee, P., Mittal, K., Soteropoulos, P., and Wei, J.J. 2007. A micro-RNA signature associated with race, tumor size, and target gene activity in human uterine leiomyomas. Genes Chromo- somes Cancer 46: 336-347.

Wienholds, E. and Plasterk, R.H. 2005. MicroRNA function in animal development. FEBS Lett. 579: 5911-5922.

$\mathrm{Xu}$, Y., Sumter, T.F., Bhattacharya, R., Tesfaye, A., Fuchs, E.J., Wood, L.J., Huso, D.L., and Resar, L.M. 2004. The HMG-I oncogene causes highly penetrant, aggressive lymphoid malignancy in transgenic mice and is overexpressed in human leukemia. Cancer Res. 64: 3371-3375.

Yanaihara, N., Caplen, N., Bowman, E., Seike, M., Kumamoto, K., Yi, M., Stephens, R.M., Okamoto, A., Yokota, J., Tanaka, T., et al. 2006. Unique microRNA molecular profiles in lung cancer diagnosis and prognosis. Cancer Cell 9: 189-198.

Yie, J., Liang, S., Merika, M., and Thanos, D. 1997. Intra- and intermolecular cooperative binding of high-mobility-group protein $\mathrm{I}(\mathrm{Y})$ to the $\beta$-interferon promoter. Mol. Cell. Biol. 17: 3649-3662.

Zaidi, M.R., Okada, Y., and Chada, K.K. 2006. Misexpression of full-length HMGA2 induces benign mesenchymal tumors in mice. Cancer Res. 66: 7453-7459.

Zamore, P.D. and Haley, B. 2005. Ribo-gnome: The big world of small RNAs. Science 309: 1519-1524.

Zhou, X., Benson, K.F., Ashar, H.R., and Chada, K. 1995. Mutation responsible for the mouse pygmy phenotype in the developmentally regulated factor HMGI-C. Nature 376: 771-774. 


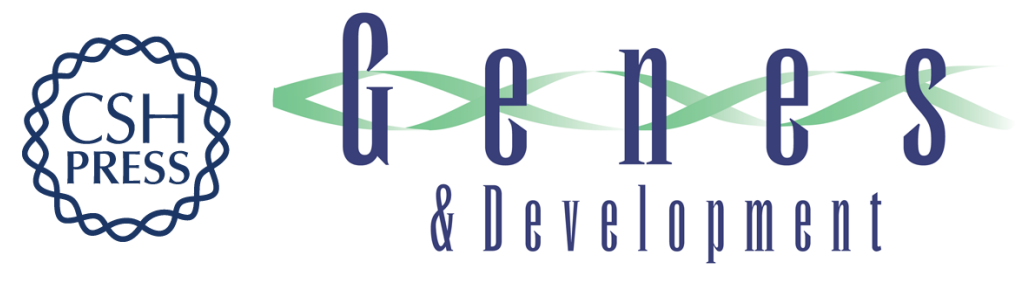

\section{Oncogenic HMGA2: short or small?}

Andrew R.J. Young and Masashi Narita

Genes Dev. 2007, 21:

Access the most recent version at doi:10.1101/gad.1554707

Related Content The tumor suppressor microRNA let-7 represses the HMGA2 oncogene

Yong Sun Lee and Anindya Dutta

Genes Dev. May , 2007 21: 1025-1030

References This article cites 44 articles, 12 of which can be accessed free at:

http://genesdev.cshlp.org/content/21/9/1005.full.html\#ref-list-1

Articles cited in:

http://genesdev.cshlp.org/content/21/9/1005.full.html\#related-urls

\section{License}

Email Alerting Receive free email alerts when new articles cite this article - sign up in the box at the top Service right corner of the article or click here.

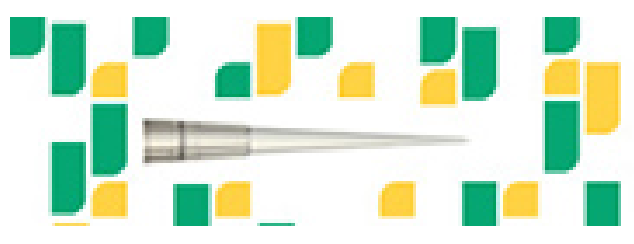

Focused on your science. 